\title{
Jogos sérios e temáticas sociais: desenvolvimento e avaliação preliminar de um jogo que aborda o tema machismo e suas reflexões provocadas
}

\author{
Bruno de Oliveira \\ Instituto UFC Virtual \\ Universidade Federal do Ceará \\ Fortaleza, Ceará, Brasil \\ brunocastroliveira@gmail.com
}

\author{
Rosilene Fernandes \\ Instituto UFC Virtual \\ Universidade Federal do Ceará \\ Fortaleza, Ceará, Brasil \\ rosilenemoufer@gmail.com
}

\author{
Izac Sidarta \\ Instituto UFC Virtual \\ Universidade Federal do Ceará \\ Fortaleza, Ceará, Brasil \\ izacsidarta@gmail.com
}

\author{
Pedro Lima \\ Instituto UFC Virtual \\ Universidade Federal do Ceará \\ Fortaleza, Ceará, Brasil \\ pffl28@gmail.com
}

\author{
Emili Farias \\ Instituto UFC Virtual \\ Universidade Federal do Ceará \\ Fortaleza, Ceará, Brasil \\ emilibf05@gmail.com
}

\section{RESUMO}

Jogos sérios oferecem potencialidades interessantes para informar as pessoas sobre temas sociais emergentes. Por exemplo, eles oferecem interatividade através da jogabilidade, um recurso distintivo, que pode envolver ativamente o jogador. Nesse contexto, o foco deste estudo é detalhar a concepção, desenvolvimento e avaliação preliminar do jogo "A Batalha de Ma'Sohora". O jogo pretende oferecer uma experiência de jogo que provoque reflexões sobre o chauvinismo masculino e está planejado para ser estendido para incluir outros temas relevantes.

\section{PALAVRAS-CHAVE}

Jogos sérios, experiência de usuário, machismo, avaliação, aplicativos móveis, design.

\section{Introdução}

O machismo é um sistema de ideias que reforça a dominação do homem sobre a mulher [9]. Essa relação de dominação apoia-se em um paradigma naturalista, que prega uma falsa natureza de superioridade dos homens e, portanto, lhes privilegia [24].

Os discursos provenientes do machismo são caracterizados como tradicionais, ou seja, estão naturalizados na sociedade contemporânea [20]. Estes discursos partem de todos os sujeitos

\footnotetext{
Permission to reproduce or distribute, in whole or in part, material extracted from this work, verbatim, adapted or remixed, as well as the creation or production from the content of such work, is granted without fee for non-commercial use, provided that the original work is properly credited.
}

IHC 2019 - Workshop sobre Interação e Pesquisa de Usuários no Desenvolvimento de Jogos (WIPlay), Outubro 21-25, 2019, Vitória, Brasil. In Anais Estendidos do XVIII Simpósio Brasileiro sobre Fatores Humanos em Sistemas Computacionais. Porto Alegre: SBC

(C) 2019 by the author(s), in accordance with the terms of the Creative Commons Attribution-NonCommercial 4.0 International Public License (CC BY-NC 4.0). sociais (homens e mulheres), que reproduzem, mesmo que de maneira inconsciente, atitudes machistas no cotidiano [23]. A busca por uma sociedade igualitária requer, portanto, o enfrentamento dos discursos cotidianos provenientes do machismo [22]. Para tanto, é necessário provocar reflexão sobre pequenas atitudes que nem sempre são entendidas como machistas, mas que reforçam a naturalização destes comportamentos.

Neste contexto, ferramentas promissoras são os Jogos Sérios Digitais (JSDs), os quais possuem finalidades outras que não apenas o entretenimento [17]. Recentemente, os JSDs têm despertado interesse de pesquisadores de diversas áreas [19] e apresentam uma interessante maneira de envolver, de forma ativa, o indivíduo [14]. Além disso, os JSDs ainda são populares entre crianças, adolescentes e jovens adultos, o que pode gerar um efeito multiplicador da mensagem a ser comunicada [21]. Finalmente, os JSDs podem ainda ser disponibilizados em dispositivos móveis, que já estão presentes nas atividades cotidianas de grande parte do público jovem e adulto [11]. Apesar de tais potencialidades, mesmo no âmbito dos jogos, as mulheres ainda se sentem subrepresentadas [6] e obrigadas a lidar com discursos machistas, como preconceitos e estereótipos negativos [2].

A partir do que foi discutido acima, o objetivo deste trabalho é apresentar a concepção e o desenvolvimento de A Batalha de Ma'Sohora, um JSD para dispositivos móveis projetado com o intuito de gerar reflexão a respeito da temática do machismo. Para tanto, serão reportados testes iniciais realizados com usuários, visando obter retornos preliminares acerca da experiência de usuário da aplicação. Desta forma, espera-se que este trabalho possa inspirar discussões iniciais interessantes acerca da utilização de JSDs para gerar reflexões sobre temáticas sociais como o machismo. 


\section{Referencial Teórico}

Pesquisadores apontam que o machismo está profundamente inserido na sociedade brasileira, possuindo extensas raízes históricas, que remontam ao período colonial $[8,10]$. No período contemporâneo, há uma lógica de subordinação feminina não apenas no espaço físico ("do lar”), mas também no espaço social [9]. Desta forma, o machismo atual muitas vezes apresenta-se de forma sutil, como em ambientes acadêmicos ou de trabalho. Este tipo de machismo é representado, por exemplo, por opiniões que expressem incapacidade feminina em tomar decisões importantes, ou atitudes que determinem a necessidade de supervisão masculina sobre elas. Tais expressões de machismo reforçam um autoritarismo que é resultado da validação da violência através da desqualificação constante das mulheres e de outros grupos vistos como minorias [9].

Neste contexto, os JSDs podem oferecer uma interessante alternativa de abordagem de temáticas sociais, como o machismo. Os JSDs podem simular situações do mundo real, ou apresentar metáforas que representem a atual condição de minorias que sejam alvos de discriminação ou preconceito. Através da interatividade -característica intrínseca da mídia videogame - os JSDs são capazes de apresentar argumentos retóricos que venham a gerar impactos emocionais e causar reflexões críticas nos jogadores [25].

Para que os objetivos sejam atingidos, um JSD deve prover uma adequada experiência do usuário. A experiência do usuário (UX) pode ser entendida como a relação subjetiva entre usuário e aplicação [16]. A UX deriva do conjunto das consequências de três estados: (i) o particular do próprio usuário (como expectativas, humor, motivações e experiências), (ii) as características do sistema (como a complexidade, a usabilidade e funcionalidade que este apresenta), e (iii) o contexto no qual ocorre a interação (como o ambiente organizacional, social).

Desta forma, a UX vai além da usabilidade da aplicação, focandose na experiência pessoal que um usuário extrai de uma interação com uma aplicação [3]. No geral, uma UX agradável e rica é o objetivo principal quando se trata do design de sistemas interativos. Além disso, a presença de uma boa experiência do usuário é fator importante para a efetividade de JSDs [18]. Logo, relacionar esses conceitos à análise dos dados obtidos através da avaliação deste trabalho, contribui para identificar a experiência obtida pela aplicação.

Com o objetivo de estudar a UX em jogos de maneira objetiva, Gámez propôs o modelo teórico Core Elements of the Gaming Experience (CEGE) [3]. De acordo com o CEGE, uma UX positiva vem de uma combinação entre: (i) o jogo e (ii) a interação do jogador com ele. Os autores subdividem estas duas categorias em diversos fatores (tais quais os gráficos, os sons, as regras, os cenários, as ações, as recompensas, os objetivos, o tempo e etc) que devem ser observados para a proposta de uma UX positiva. É importante ressaltar que, de acordo com os autores, a mera observância de tais fatores não é suficiente para determinar que uma UX será positiva. Mas a ausência de alguns deles pode indicar eventuais problemas na UX. Em um estudo posterior [4], os autores desenvolveram um questionário intitulado Core Elements of the Gaming Experience Questionnaire (CEGEQ). CEGEQ é um instrumento com 38 questões de escala Likert [1], e que foi previamente validado [4]. Nesta pesquisa foi utilizado CEGEQ para investigar a UX provida pelo jogo A Batalha de Ma'Sohora.

\section{O jogo A Batalha de Ma'Sohora}

A aplicação avaliada nesta pesquisa é A Batalha de Ma'Sohora, um JSD para dispositivos móveis, projetado com o intuito de gerar reflexão acerca de temáticas sociais como o machismo.

\subsection{Concepção}

A concepção da ideia seguiu o processo de design centrado no usuário. Este consiste em um conjunto de estratégias de desenvolvimento de aplicações que busca aproximar o usuário do processo de criação [15]. Com esta abordagem, buscou-se atingir dois objetivos iniciais: (i) identificar um possível público-alvo interessado na aplicação, e (ii) entender quais os preconceitos mais presentes entre o público pesquisado.

Desta forma, foi realizada uma pesquisa através de um questionário online (disponível em: http://bit.ly/2lUABwf) para colher as informações desejadas. Foram colhidas respostas de 154 usuários que (pela conveniência do estudo considerando as restrições de tempo e recursos) eram, majoritariamente, estudantes universitários do estado do Ceará.

\subsubsection{Identificação de potencial público-alvo}

Para a identificação do público-alvo, foram elaboradas duas questões: “qual a sua idade?” e "qual a sua orientação de gênero?”.

Como pode ser observado na Figura 1a, não há diferença significativa com relação à orientação de gênero, já que $49,7 \%$ dos pesquisados se identificavam com o gênero masculino e 48,3\% com o gênero feminino. Com relação à faixa etária (ver Figura 1b), como já esperado para um público universitário, a maior quantidade de pessoas $(84,3 \%)$ possui entre 15 e 29 anos. Especificamente, há uma diferença significativa na faixa etária entre 20 e 24 anos, que representa $50,3 \%$ de todos os respondentes do questionário.

Com estes dados, foi escolhido um público-alvo de jovens entre 20 e 24 anos como a faixa etária prioritária para A Batalha de Ma'sohora. 
Jogos sérios e temáticas sociais: Desenvolvimento e avaliação preliminar de um jogo que aborda o tema machismo e suas reflexões provocadas

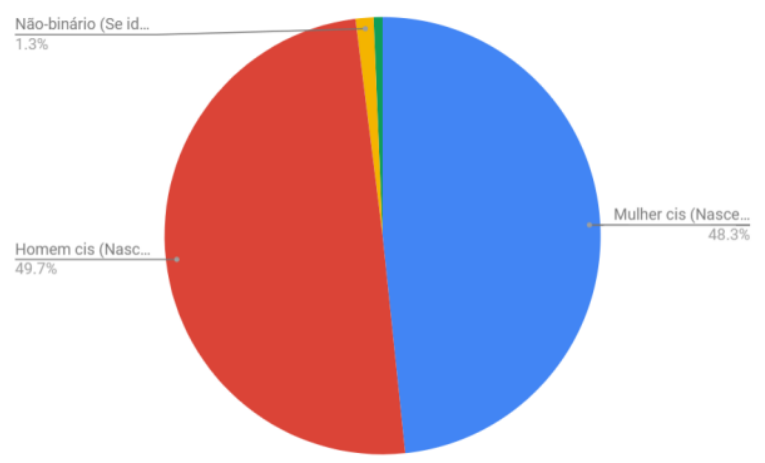

Figura 1a: Resultados da pesquisa sobre preconceito (Resultado referente à identidade de gênero)

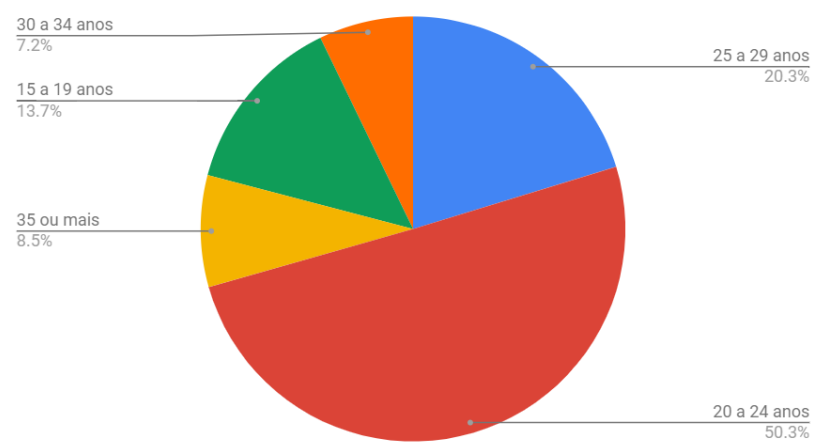

Figura 1b: Resultados da pesquisa sobre preconceito referente à faixa etária.

\subsubsection{Preconceitos mais frequentes}

Para a identificação dos preconceitos mais frequentes, foram elaboradas duas questões: "você já foi vítima de algum tipo de preconceito?" e "caso já tenha sofrido algum preconceito, quais foram?”.

Como pode ser observado na Figura 2a, A maioria dos respondentes $(78,3 \%)$ indicou já ter sido vítima de algum tipo de preconceito, o que corrobora com a ideia pré-concebida de que este é um tema relevante para o público-alvo pesquisado. Além disso, como todos os preconceitos abordados tiveram representatividade relevante (ver Figura 2b), buscou-se uma solução que contemplasse um tipo de narrativa a qual pudesse abranger os quatro preconceitos identificados. Desse modo, considerando a finalidade de comunicar a mensagem de forma didática, foi adotada a ideia de abordar os preconceitos de forma separada, com capítulos divididos dentro do jogo.

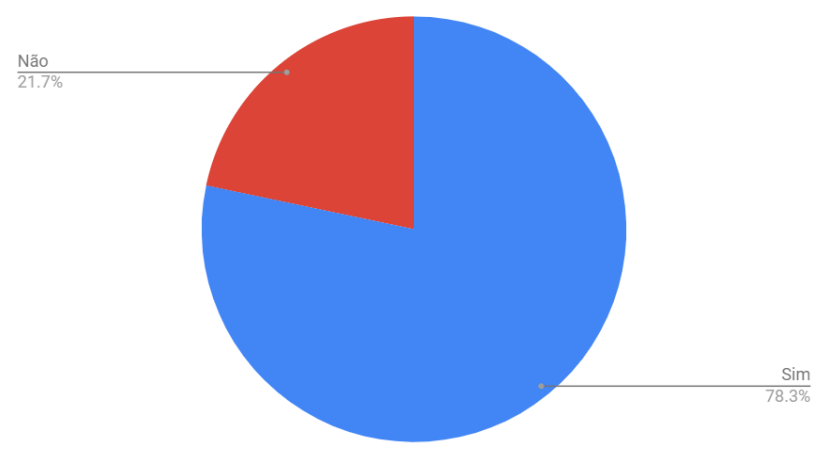

Figura 2a: Resultados da pesquisa sobre preconceito referente à pergunta: "já sofreu algum tipo de preconceito?".

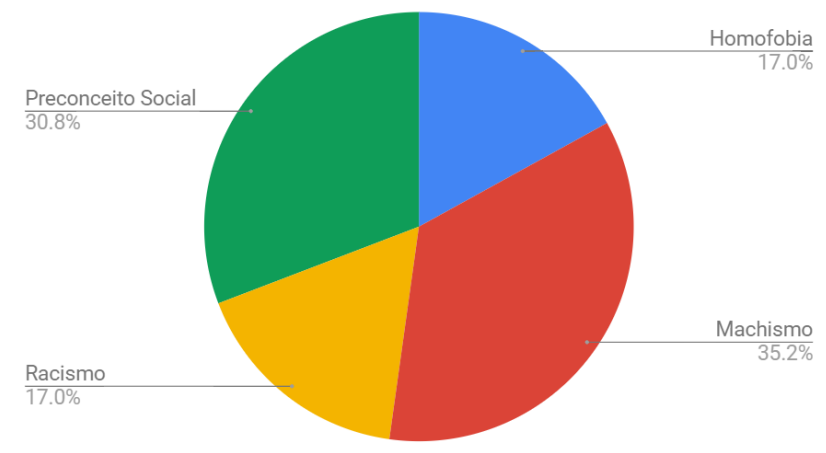

Figura 2b: Resultados da pesquisa sobre o preconceito referente à pergunta "caso já tenha sofrido algum preconceito, quais foram?".

Além de planejar separadamente a narrativa dividida para cada preconceito, considerou-se a familiaridade do público-alvo com dispositivos móveis [11] e JSDs [21], e as potencialidades destes em comunicar mensagens [17]. Considerando essas informações, propôs-se o JSD A Batalha de Ma'Sohora. O nome do jogo faz referência aos quatro tipos de preconceitos identificados na pesquisa: MA, para o machismo; SO, para o preconceito social; HO, para homofobia; e RA para o racismo.

No contexto deste trabalho, estão implementados apenas os dois capítulos iniciais dA Batalha de Ma'Sohora, que se referem exclusivamente ao machismo. Apesar deste ter sido o preconceito mais presente de acordo com a pesquisa, 41,3\% dos usuários informaram nunca o haver praticado. Acredita-se que a naturalização deste preconceito [24] pode ter relação com estes dados, o que torna o machismo ainda mais relevante de ser pesquisado. 


\subsection{Narrativa}

A Batalha de Ma'Sohora ambienta-se em uma distopia, onde os preconceitos e discriminações tornaram-se tão comuns que assumiram formas físicas, não havendo mais necessidade de se manifestarem através de pessoas.

$\mathrm{Na}$ história, a piloto Elena, ao observar a expressiva ausência feminina nas missões em campo, se alista na intenção de cooperar no combate contra os inimigos. Contudo, sua aceitação na equipe é dificultada pelo Capitão V, responsável por todo o planejamento da missão. Elena se vê desafiada a provar para o capitão que seu potencial é igual ao de qualquer outro recruta e que ela merece estar na missão. Este trecho da narrativa é comunicado inicialmente quando o jogador executa o jogo pela primeira vez, através de cutscenes, como a da Figura 3.

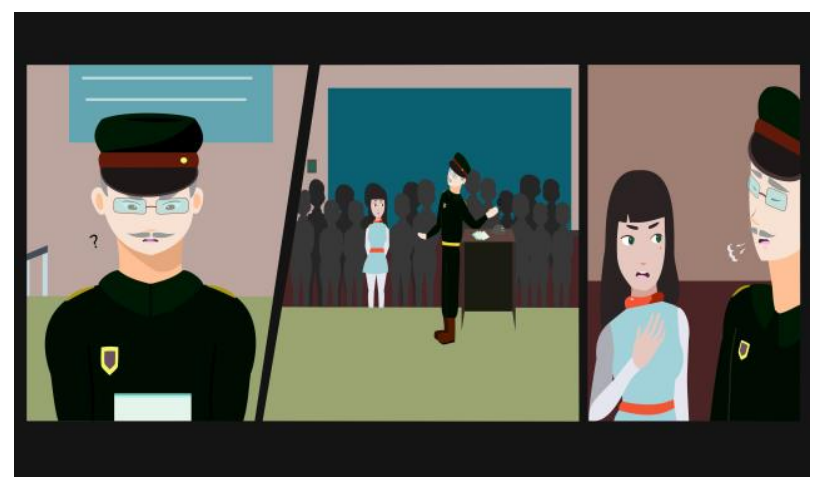

Figura 3: Cutscene de "A Batalha de Ma'Sohora": o alistamento de Elena.

A partir disso, o jogador, no papel da personagem principal, enfrenta as missões nas quais terá de provar sua capacidade passando por dificuldades, pré-julgamentos, imposições e desafios que alguém, vítima do machismo, vivencia diariamente. Essas dificuldades estão atreladas à temática e são exploradas tanto através da narrativa do jogo quanto dentro dele, no gameplay, por meio de ações que o usuário executa e observa durante seu contato com a aplicação. Como dito anteriormente, em sua versão atual, estão implementados os dois primeiros capítulos de A Batalha de Ma'Sohora.

O primeiro capítulo inicia em um momento introdutório, de apresentação, para que o usuário se habitue ao modo de jogo, enfrentando apenas um inimigo. São introduzidos os controles, os itens da interface, e não é possível que o jogador perca neste momento. Após esse tutorial, o personagem joga pela primeira fase, com inimigos que são introduzidos regularmente. Após um minuto e meio de gameplay, caso o jogador não tenha sido derrotado, alguns inimigos aparecem na tela, e o jogador é apresentado ao personagem Lúcio, um colega de Elena que intervém nas ações da personagem principal, subestimando-a. Neste momento, por exemplo, o Lúcio - que possui uma nave de qualidade superior a de Elena - aparece destruindo todos os inimigos da tela, e encerrando a fase (ver Figura 4).

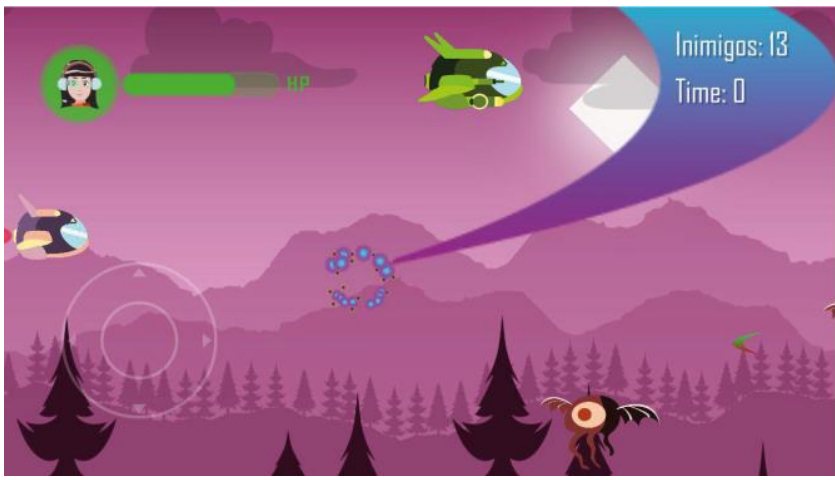

Figura 4: A chegada de Lúcio, com uma arma muito superior à da Helena.

Após o evento do final do primeiro capítulo, Elena se sente inferiorizada e decide partir numa próxima missão onde ela deve recrutar outras mulheres para ajudá-la. Esta parte da narrativa é comunicada através de um diálogo in-game com o Capitão V (ver Figura 5).

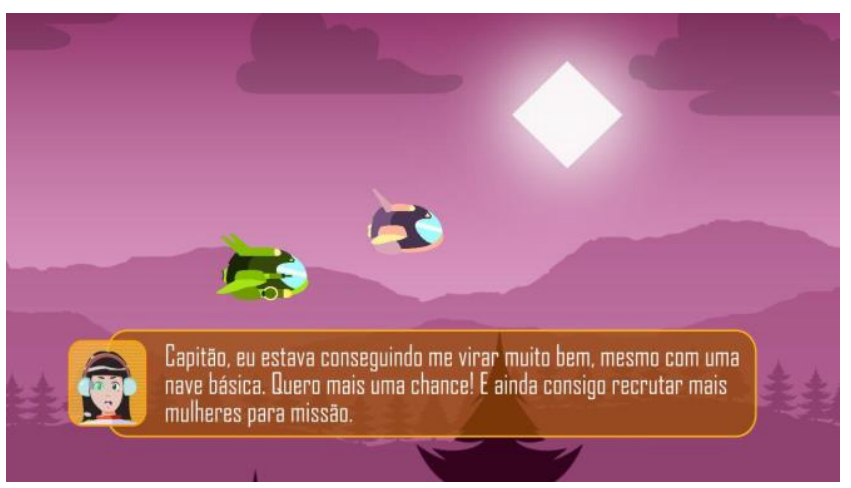

Figura 5: Diálogo apresentado entre capítulos 1 e 2 .

No segundo capítulo, são introduzidas as mecânicas de captura de aprimoramentos para a nave e do resgate de recrutas mulheres. O objetivo é resgatar oito recrutas. Novamente há a presença do Lúcio que, ao tentar combater os inimigos da Elena acaba atacando-a. Ou seja, para que concluir o capítulo, o jogador deve também desviar das investidas do Lúcio.

A versão atual do jogo termina ao final do segundo capítulo, quando a Elena consegue resgatar as recrutas e diz estar pronta para a batalha.

\subsection{Jogabilidade}

A Batalha de Ma'Sohora é baseado nas mecânicas de shooters, que são jogos de ação na qual o jogador deve atacar os inimigos com projéteis, ao mesmo tempo que se esquiva dos projéteis inimigos. A escolha dessa mecânica deu-se pela sua simplicidade no quesito aprendizado, além de sua popularidade em dispositivos móveis.

Já no âmbito dos controles, como se pode ver na Figura 6, o jogador manipula uma nave através de um controle fixo que simula um botão analógico. Ademais, para derrotar os inimigos, o usuário deve interagir com um clique na segunda metade da tela, 
Jogos sérios e temáticas sociais: Desenvolvimento e avaliação preliminar de um jogo que aborda o tema machismo e suas reflexões provocadas

disparando tiros ilimitadamente. O limite definido para o jogador foi o sistema de "vida", que consiste em uma barra que define o tanto de dano que pode receber antes que precise reiniciar a fase.

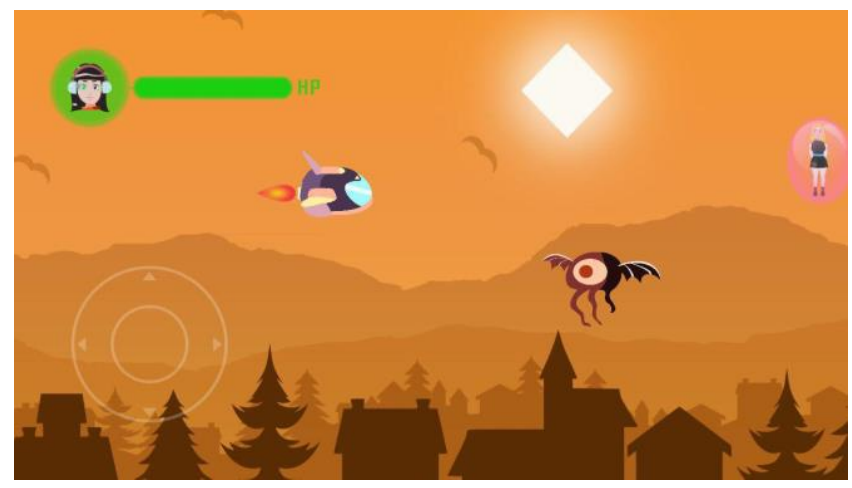

Figura 6: Exemplo do momento de jogabilidade.

Um desafio para os desenvolvedores foi tentar garantir que o foco do jogador esteja na mensagem a ser passada, e não no desafio técnico de esquivar-se de projéteis e atacar os inimigos. Para tanto, foi utilizado um gameplay mais lento, com menos inimigos e projéteis na tela em comparação com outros jogos semelhantes comerciais. Além disso, como descrito na Seção 3.2, diversos itens apresentam a narrativa, seja através de cutscenes, diálogos ingame, ou mesmo ações do personagem Lúcio.

\subsection{Identidade Visual}

A Batalha de Ma'Sohora conta com um design minimalista no intuito de diminuir a carga cognitiva associada a compreensão do cenário. Desta forma, espera-se possibilitar que o usuário foque a sua atenção nos fatores que são importantes para comunicar a mensagem desejada e, ainda assim, compreenda seus objetivos intuitivamente.

A paleta de cores selecionada para representar os ambientes, personagens e elementos dA Batalha de Ma'Sohora foi pensada de acordo com a temática e a narrativa do jogo. Tons de lilás foram utilizados na tela inicial (ver Figura 7) e no primeiro capítulo do jogo, no qual a personagem principal, Elena, tem sua primeira oportunidade de provar que suas habilidades são equivalentes as de qualquer outro recruta. Segundo Giannotti [12], na década de 70, várias mulheres assumiram a cor lilás como sendo específica de sua luta.

No segundo capítulo, as cores selecionadas para o cenário seguem uma perspectiva de tons mais quentes, contrastando com a fase anterior e evidenciando na narrativa a mudança de ambientes, da floresta para o campo, demonstrando que o inimigo está cada vez mais próximo das áreas urbanas. A cor selecionada foi laranja (ver Figura 6), explorada em sua escala monocromática no intuito de manter a ideia inicial de cores mais quentes, que trabalham a sensação de firmar energias dentro de nós [13]. Tal energia é importante para o jogador ao entrar na segunda fase do jogo, pois esta apresenta dificuldade crescente, com maior variação de
WIPlay'19, 21 a 25 de Outubro de 2019, Brasil

inimigos e seus ataques, além de novos objetivos e tarefas a serem realizados.

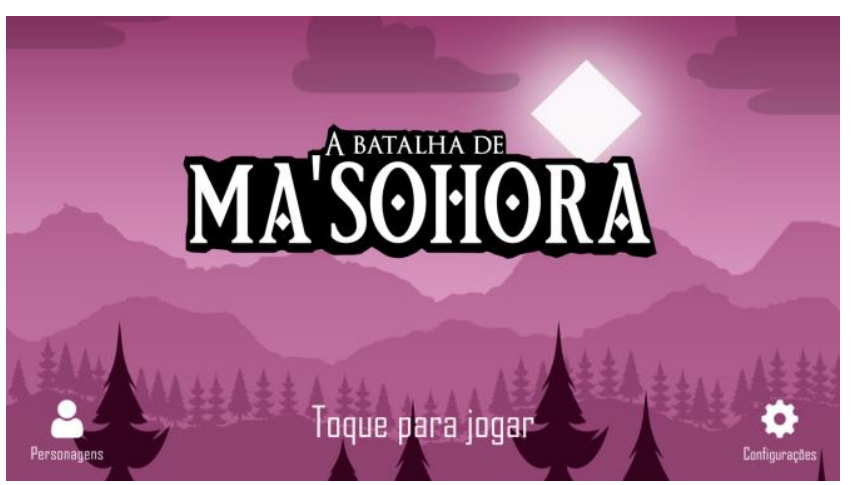

Figura 7: Tela inicial do jogo "A Batalha de Ma'Sohora"

\section{Avaliação}

Após várias rodadas de testes e atualizações iterativas, que incluíram momentos com usuários e especialistas, foi possível realizar testes para investigar preliminarmente a UX gerada pela interação com A Batalha de Ma'Sohora. Para tanto, foram utilizados dados qualitativos e quantitativos para analisar a distribuição de fenômenos interessantes no grupo de testes [8,17].

A avaliação ocorreu na Universidade Federal do Ceará e na Universidade Estadual do Ceará nos dias 21 de junho de 2019 e 04 de julho de 2019, respectivamente. Em ambas as universidades, as avaliações foram feitas em salas de aula com todos os aparatos necessários.

Foram utilizadas três técnicas para a coleta de dados: observação, questionários e entrevista semiestruturada. Desta forma, o processo de avaliação foi dividido em cinco fases: triagem dos usuários, questionário sociodemográfico, observação durante contato do usuário com a aplicação, questionário CEGEQ e entrevista.

\subsection{Triagem}

A triagem dos usuários foi realizada para encontrar indivíduos que possuem nível básico de inglês, para responder o questionário CEGEQ, e familiaridade com jogos para dispositivos móveis. Foram selecionados um total de 16 usuários, com faixa etária entre 20 a 24 anos, universitários, igualmente divididos entre homens e mulheres no intuito de observar como ambos os gêneros compreendem a temática em suas respectivas realidades.

Para realizar a coleta de dados, foram necessários dois avaliadores, com experiência prévia para a avaliação, e um mediador, para explicar todo o procedimento para os usuários e guiá-los até o final do processo. Os materiais necessários para tal foram folhas A4, pranchetas e canetas. 
O mediador, antes de iniciar a avaliação, explica o funcionamento desta. São informadas quantas etapas estão presentes no processo e o que o usuário tem e pode fazer. A este também é informado sobre todos os aspectos éticos e das informações gerais acerca do propósito e a finalidade da avaliação. Parte do processo possui gravação de áudio, logo, todos os participantes assinaram um Termo de Consentimento Livre e Esclarecido.

\subsection{Questionário sociodemográfico}

O questionário sociodemográfico foi aplicado para identificar informações gerais sobre os usuários. Tais informações englobam sua faixa etária, cor/raça, orientação sexual, identidade de gênero, o nível de familiaridade com jogos para smartphones e o nível de inglês, totalizando em 6 perguntas.

\subsection{Observação do usuário com a aplicação}

Na terceira fase, o usuário tem contato com o jogo. É informado que este momento tem duração de dez a quinze minutos, podendo o indivíduo parar quando achar oportuno. É nessa fase que o método observacional é utilizado pelos dois avaliadores os quais identificam e analisam as ações, comportamentos, reações e atitudes do usuário durante seu contato com o jogo. Os avaliadores ficam posicionados atrás do usuário de maneira que possam observá-lo, sem, todavia, interferir no contato deste com a aplicação.

\subsection{CEGEQ}

Ao fim da fase de contato com a aplicação, o mediador aplica o questionário CEGEQ. A ferramenta foi utilizada no seu idioma original (inglês) pois já havia sido previamente validada desta forma. Uma tradução sem a devida validação poderia interferir na interpretação do usuário e na validade dos dados coletados.

\subsection{Entrevista}

A entrevista corresponde à quinta fase do processo de avaliação. Nela, os usuários foram abordados com relação à perspectiva do jogo de modo geral e quanto a narrativa que este apresentou. Foram necessários, nessa fase, o uso equipamentos para gravação, previamente autorizada pelos usuários.

Para a entrevista, foram elaboradas cinco questões, que se relacionavam com três objetivos principais: (i) coletar a impressão geral do usuário acerca da interação com o jogo, deixando-o livre para comentar acerca de quaisquer aspectos, como controles, narrativa, design, dentre outros; (ii) observar a compreensão da temática, verificando a comunicação da mensagem desejada e o impacto por ela gerada; e (iii) relacionar o conteúdo abordado com a sua aplicação no mundo real, de forma a indicar a eficiência dA Batalha de Ma'Sohora. A Tabela 1 resume as perguntas elaboradas e seus objetivos relacionados.

Os dados foram analisados e interpretados por dois pesquisadores utilizando a técnica de Análise de Conteúdo [5], e, como resultado, foram obtidas informações úteis relacionadas à qualidade do jogo, aos possíveis aprimoramentos e, às impressões geradas pela temática abordada.

\begin{tabular}{|c|c|}
\hline Objetivo & Questão da entrevista \\
\hline Impressão geral & $\begin{array}{l}\text { O que você achou do jogo? Como foi sua } \\
\text { experiência de modo geral? }\end{array}$ \\
\hline \multirow[b]{2}{*}{$\begin{array}{l}\text { Compreensão } \\
\text { da temática }\end{array}$} & O quanto da história você pôde entender? \\
\hline & $\begin{array}{l}\text { Em algum momento você se sentiu } \\
\text { incomodado com o que foi apresentado na } \\
\text { história? }\end{array}$ \\
\hline \multirow{2}{*}{$\begin{array}{l}\text { Aplicação no } \\
\text { mundo real }\end{array}$} & $\begin{array}{l}\text { Você pode relacionar o que foi } \\
\text { apresentado no jogo com a vida real? }\end{array}$ \\
\hline & $\begin{array}{l}\text { Você acredita que o jogo pode impactar a } \\
\text { sociedade de alguma forma? }\end{array}$ \\
\hline
\end{tabular}

Tabela 1: Objetivos e questões da entrevista

\section{Resultados e Discussão}

Esta Seção apresenta, resumidamente, os resultados obtidos da análise de dados das avaliações realizadas com os usuários. Para tanto, foram identificadas categorias que se referem à experiência dos usuários de acordo com o modelo CEGE: a relação dos usuários com o jogo, o controle do jogo, a compreensão e execução das tarefas e os aspectos visuais e sonoros. As Seções 5.1 a 5.4 detalham cada uma destas categorias, apresentando os resultados obtidos pelos métodos de coleta (observação, questionário e entrevista) e indicando possíveis informações relevantes resultantes da análise destes dados. A Seção 5.5 tem maior foco na discussão sobre a compreensão do tema machismo trabalhado na aplicação "A Batalha de Ma’Sohora".

É importante ressaltar que tanto os métodos utilizados, como a quantidade de usuários abordados não nos permite fornecer conclusões definitivas acerca da UX ou da efetividade dA Batalha de Ma'Sohora. Entretanto, esperamos que a análise dos dados obtidos até agora seja suficiente para inspirar elucubrações interessantes acerca da UX, JSDs e temáticas sociais.

\subsection{A relação dos usuários com o jogo}

Esta categoria relaciona-se à visão que os usuários têm sobre o tipo de jogo, sobre o jogo propriamente dito e quais os sentimentos despertados pela interação.

De forma geral, os resultados indicam que a aplicação proporcionou um momento positivo aos usuários. Dez deles fortemente concordaram com a afirmação sobre "gostar do jogo" (ver Figura 8), ou seja, na escala do questionário CEGEQ, dez indivíduos atribuíram 7. Outros dois usuários atribuíram 6 à afirmação, ainda mantendo-se numa escala positiva. Resultados positivos também foram observados para as afirmações: "jogaria novamente" (ver Figura 9); "gastaria mais tempo jogando"; e "o jogo motivou a continuar jogando".

Os dados qualitativos também corroboram a sensação de uma experiência positiva. $\mathrm{Na}$ observação foi possível identificar 
Jogos sérios e temáticas sociais: Desenvolvimento e avaliação preliminar de um jogo que aborda o tema machismo e suas reflexões provocadas

momentos de diversão explícita (como sorrisos audíveis), bem como nas entrevistas os usuários também manifestaram reações positivas relacionadas ao seu momento com o jogo, expressandose através de comentários, denotando boas experiências com a aplicação de forma geral.

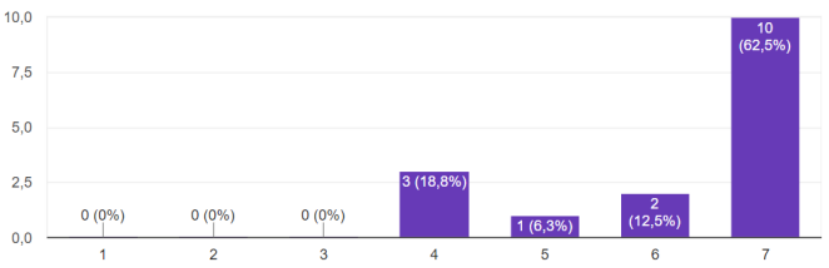

Figura 8: Gráfico de respostas do CEGEQ quanto ao item "I liked the game"

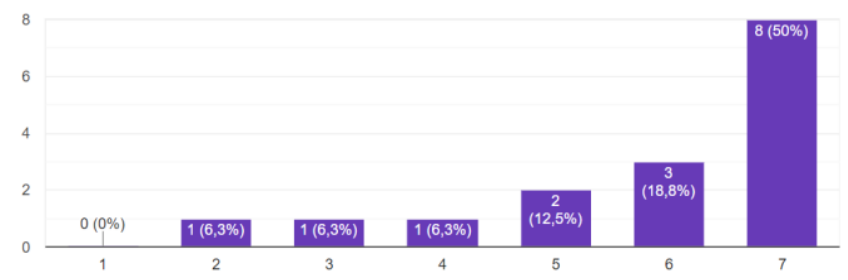

Figura 9: Gráfico de respostas do CEGEQ quanto ao item "I would play this game again"

\subsection{Controle do jogo}

Esta categoria representa a satisfação dos usuários com os controles apresentados no jogo, se estes obedeciam a seus comandos, se eram utilizados da maneira esperada e se os usuários conseguiam executar determinadas ações durante seu contato com a aplicação.

Com relação à afirmação "os controles responderam da forma que eu esperava”, os índices (ver Figura 10) - apesar de mais espaçados quando comparados à categoria anterior (ver Seção 5.1) - ainda demonstram grau de positividade $(62,5 \%$ indicaram concordância com a afirmativa, enquanto $31,4 \%$ discordaram). Resultados mais expressamente positivos foram encontrados em relação à afirmativa "eu me lembro das ações que os controles executavam" (ver Figura 11), para a qual apenas 1 usuário expressou discordância.

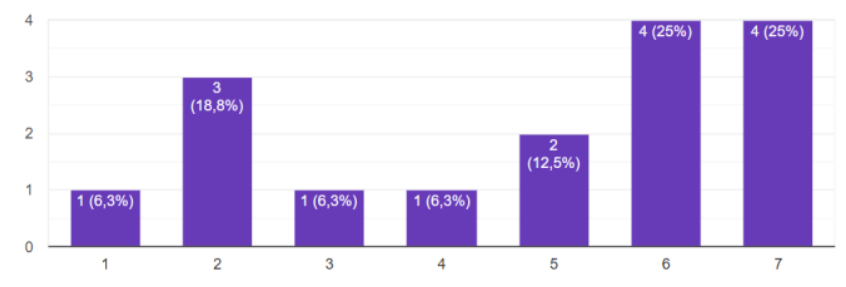

Figura 10: Gráfico de respostas do CEGEQ quanto ao item "The controller responded as I expected"
WIPlay'19, 21 a 25 de Outubro de 2019, Brasil

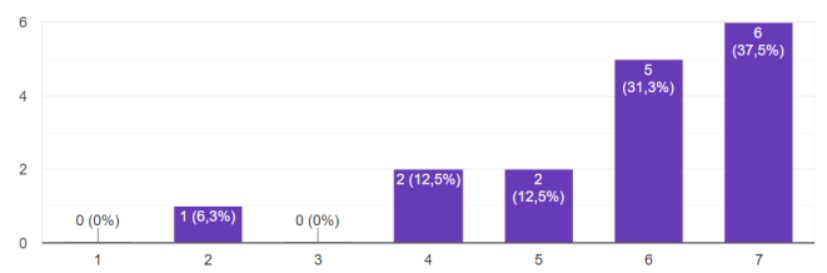

Figura 11: Gráfico de respostas do CEGEQ quanto ao item "I remember the actions the controller performed"

Os dados qualitativos apresentam também algumas controvérsias. De forma geral, foi possível averiguar na observação da interação que os usuários conseguiram controlar a nave sem prévia instrução, o que indica um relativo sucesso das metáforas escolhidas para representar os controles. No entanto, nas entrevistas os usuários informaram que, apesar de ter compreendido o modo de funcionamento do controle de movimentação da nave, sentiram dificuldades para movimentá-la devido a velocidade com a qual esta se movia (lenta demais). Em contraposição, outros usuários caracterizaram a velocidade como desafiadora, relacionando o ocorrido com a narrativa exposta no jogo, na qual a personagem recebia uma nave de capacidade inferior, pelo simples motivo de ser mulher.

Os controles foram um aspecto desafiador no desenvolvimento dA Batalha de Ma'Sohora. Os shooters são jogos que requerem ação e reflexos rápidos e coordenados do jogador. Os dispositivos móveis carecem de botões, que adicionam retorno tátil importante para o usuário neste tipo do jogo. Como o foco do jogo estava na mensagem e não em um desafio de técnica, a equipe tomou a decisão de diminuir a velocidade geral do jogo (nave e inimigos). Pôde-se observar que o resultado geral não foi satisfatório para todos os participantes, apesar de tê-lo sido para a maioria.

O controle do jogo é um aspecto fundamental o qual acreditamos que possa ser melhorado. Contudo, mesmo com a presença de pequenas dificuldades, acreditamos que os dados indicam que a experiência durante o jogo não foi arruinada.

\subsection{Compreensão e execução de tarefas}

Esta categoria refere-se à compreensão dos usuários com relação aos elementos presentes na aplicação que direcionam o cumprimento dos objetivos e à facilidade para identificar o que era necessário para atingir as metas propostas pelo jogo.

Quanto à compreensão das regras do jogo pelos jogadores (ver Figura 12), as informações coletadas apresentam alto nível de positividade. Mais de $90 \%$ dos jogadores concordaram em ter entendido as regras do jogo, sendo $68,8 \%$ destes de forte concordância com a assertiva. 


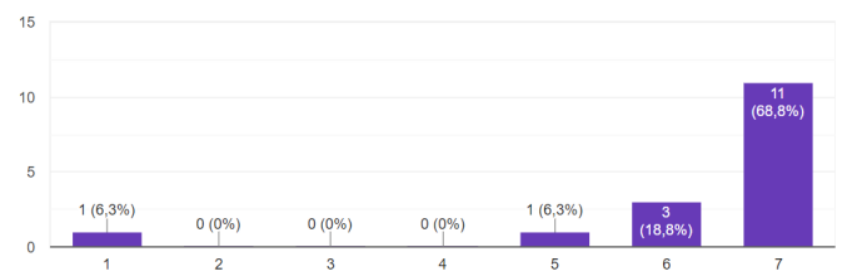

Figura 12: Gráfico de respostas do CEGEQ quanto ao item "I understood the rules of the game"

Novamente, mais de $50 \%$ dos usuários apresentaram respostas positivas quanto à afirmação "fui capaz de identificar tudo o que precisava durante o jogo" (ver Figura 13). Um quarto desses usuários concordaram fortemente com a assertiva, atribuindo 7 , e outros 5 e 6 , com $12,5 \%$ e $37,5 \%$, respectivamente.

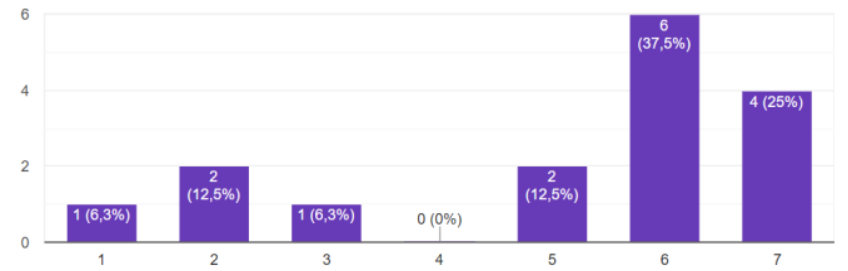

Figura 13: Gráfico de respostas do CEGEQ quanto ao item "I was able to see on the screen everything I needed during the game"

Nas entrevistas alguns usuários relataram que a ausência de especificação de informações referentes à quantidade de inimigos que devem ser abatidos no primeiro capítulo do jogo gerou dúvidas quanto ao objetivo requerido. No entanto, os mesmos usuários alegaram que a falta dessa informação não afetou de maneira considerável sua experiência com o jogo. Outro apontamento, agora sobre o segundo capítulo, foi da ausência da informação de que o aparecimento e colisão do Lúcio acarretaria a morte do jogador (o Lúcio era anunciado através de uma "seta" indicando o sentido do qual ele chegaria). Tal ocorrência gerava dúvidas nos usuários quanto ao motivo de estarem sendo abatidos e reiniciando a fase. Sobre os outros elementos presentes nas fases, os usuários não identificaram dificuldades na compreensão e na interpretação, demonstrando conhecimento quanto aos seus significados e finalidades.

\subsection{Aspectos visuais e sonoros}

Esta categoria aborda dois aspectos principais da interface apresentada ao usuário: gráficos (cores, tipografia e outros elementos) e sonoros (músicas e efeitos sonoros, por exemplo).

Os resultados do CEGEQ para esta categoria foram categoricamente positivos. Não foram apresentados resultados negativos quanto aos gráficos do jogo, aos efeitos sonoros e à relação entre esses dois elementos.

Na Figura 14 é possível constatar que os usuários em sua totalidade informaram que os gráficos estavam apropriados para o tipo de jogo apresentado, sendo $75 \%$ dessas afirmações categorizadas como "concordo fortemente".

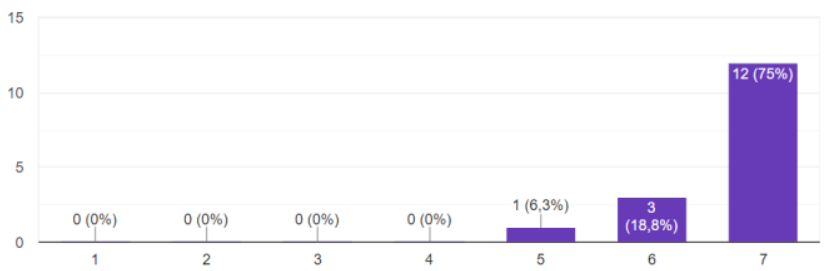

Figura 14: Escala de resposta CEGEQ quanto à afirmação "The graphics were appropriate for the type of game".

Os usuários também concordaram de maneira unânime acerca dos efeitos sonoros e o quão apropriado estavam, apresentando 43,8\% e 56,3\%, marcando 7 e 9 na escala, respectivamente (ver Figura 15).

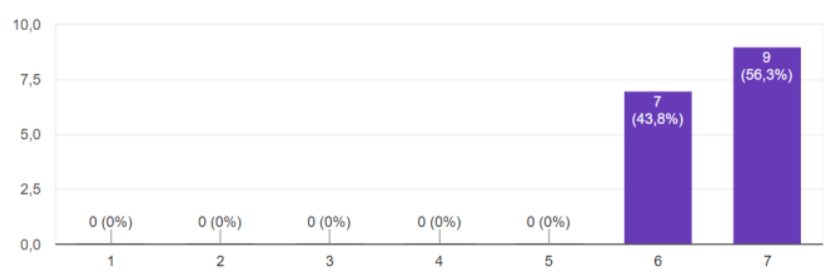

Figura 15: Escala de resposta CEGEQ quanto à afirmação "The sound effects of the game were appropriate".

Finalmente, no quesito da relação entre elementos gráficos e sonoros, a opinião dos usuários foi, novamente, unânime sobre a afirmativa "os gráficos e efeitos sonoros do jogo estavam relacionados" (ver Figura 16), sendo 11 das respostas de forte concordância, atribuição 7 na escala Likert.

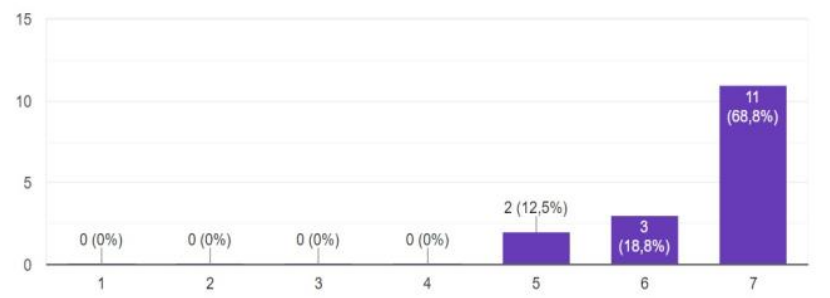

Figura 16: Escala de resposta CEGEQ quanto à afirmação "The graphics and sound effects of the game were related".

Os resultados positivos desta categoria nos levam a crer que os aspectos visuais e sonoros dA Batalha de Ma'Sohora estão bem colocados, e atendendo às expectativas dos jogadores. Esta afirmação ainda é suportada pelos dados qualitativos: na observação da interação dos usuários foi possível observar, em mais de uma oportunidade, reações de surpresa positiva quando a tela inicial do jogo foi vista pela primeira vez. 
Jogos sérios e temáticas sociais: Desenvolvimento e avaliação preliminar de um jogo que aborda o tema machismo e suas reflexões provocadas

\subsection{Associação ao tema machismo}

Além das quatro categorias relacionadas ao CEGE e detalhadas nas Seções 5.1 à 5.4, durante as entrevistas investigou-se preliminarmente a associação do jogo apresentado à temática do machismo proposta pelos desenvolvedores. Mais uma vez, esta investigação não é capaz de comprovar a efetividade do jogo em transmitir a mensagem desejada, mas, esperamos, pode inspirar caminhos interessantes para trabalhos futuros.

Todos os usuários relataram ter compreendido e relacionado claramente o jogo com aspectos associados ao machismo e afirmaram ter noção de que o exposto é um exemplo de discriminação presente na sociedade em que se encontram. Alguns relataram ter passado por experiências semelhantes ou ouvido relatos de pessoas próximas vítimas desse tipo de preconceito. Outros afirmaram ainda que propostas como A Batalha de Ma'Sohora devem ser mais divulgadas no intuito de amenizar a discriminação existente de vários grupos taxados como minorias da sociedade. Estes resultados deixam a impressão de que, de forma geral, o jogo oferece uma experiência interessante e aborda um tema relevante.

Um fato interessante advém da comparação entre os resultados obtidos através do questionário CEGEQ e das entrevistas. Praticamente os mesmos usuários que concordaram com a afirmação "havia momentos do jogo em que eu não estava fazendo nada" também informaram que havia desvantagem entre a nave que eles utilizaram, da personagem mulher, e a do personagem masculino. Tal afirmação se deve ao fato de que, no momento que o personagem homem aparece durante o jogo, ele consegue fazer todo o trabalho sozinho, diminuindo o que a personagem mulher, representada pelo jogador, havia feito durante a fase. Desta forma, um dado que pareceria negativo a princípio (alguns jogadores afirmarem que havia momentos de inatividade) pode indicar que o gameplay atingiu sucesso em comunicar a mensagem desejada.

Neste contexto, outro fato interessante a ser destacado é que alguns usuários conseguiram identificar características do machismo não somente nas cutscenes (que são momentos de apresentação direta da narrativa), mas também durante momentos in-game. Algumas das observações dos usuários quanto ao quesito foram "me senti diminuída com os poderes do outro personagem quando comparado aos meus"; "por que ela vai precisar de alguém a seguindo? Ela pode fazer o trabalho sozinha"; "por mais que estivesse fazendo tudo certo e conseguindo atingir meus objetivos o tal capitão não reconhecia meu trabalho, apenas do outro piloto". Acreditamos que estes são indicadores interessantes acerca do sucesso do gameplay desenvolvido: A Batalha de Ma'Sohora parece ser capaz de entregar sua mensagem através da interatividade. Por considerarmos que a interatividade é, em último caso, o principal fator que diferencia a mídia videogame, esperamos que A Batalha de Ma'Sohora seja capaz de explorá-la em toda a sua potencialidade e entregar uma mensagem de uma forma diferente do que seria possível por outros meios.
WIPlay'19, 21 a 25 de Outubro de 2019, Brasil

\section{Conclusão}

JSDs são capazes de oferecer experiências prazerosas e afetivas, de aprendizado, de simulações e criatividade. O objetivo deste trabalho foi apresentar a concepção e o desenvolvimento de A Batalha de Ma'Sohora, um JSD para dispositivos móveis projetado com o intuito de gerar reflexão a respeito da temática do machismo.

De forma geral, a avaliação preliminar realizada indica que A Batalha de Ma'Sohora proporciona uma experiência positiva, considerando aspectos que impactam a UX, tais quais a relação dos usuários com o jogo, o controle do jogo, a compreensão e execução das tarefas e os aspectos visuais e sonoros. Apesar de pequenos problemas detectados, especialmente no controle do jogo, acreditamos que os resultados majoritariamente positivos indicam que A Batalha de Ma'Sohora é uma ferramenta promissora, que deve ser atualizada para fornecer uma melhor experiência.

A investigação inicial realizada também indica que a reflexão a respeito da temática do machismo pode ser alcançada através da interação com A Batalha de Ma'Sohora. Pode-se destacar, por exemplo, a unanimidade dos usuários em acreditar que a aplicação possa servir como um instrumento facilitador da discussão do tema na sociedade e, principalmente, nas escolas. Consideramos ainda especialmente válido que os jogadores tenham percebido a mensagem em momentos in-game, o que é um indicativo de que o jogo comunica a sua mensagem através do gameplay, explorando, portanto, o potencial da mídia videogame.

Os próximos passos incluem, além da realização de ajustes nos controles, a introdução dos outros capítulos contemplando os demais preconceitos detectados: homofobia, racismo e preconceito social. Em seguida, deverá ser realizada uma avaliação mais robusta, com um número maior de usuários, que permita a geração de dados quantitativos estatisticamente significativos, que possam embasar afirmações conclusivas acerca da experiência gerada e da efetividade do jogo.

Esperamos que o presente estudo possa estimular desenvolvedores, designers e pesquisadores na produção e avaliação de outros jogos com temáticas sociais. Tais iniciativas, somadas ao aumento da visibilidade deste debate (com movimentos sociais como o \#MeToo [7], ou o aumento da publicidade das pesquisas do campo das Ciências Sociais), podem oferecer ferramentas auxiliares para o combate dos preconceitos profundamente arraigados na sociedade.

Finalmente, acreditamos que, através da interatividade, A Batalha de Ma'Sohora é capaz de entregar mensagens de uma maneira distinta de que seria possível por outros meios, explorando de maneira lúdica e ativa as consequências dos preconceitos, gerando reflexões críticas nos jogadores. Além do mais, a presença de protagonistas femininas e o enredo próximo de situações do mundo real pode empoderar outras mulheres e inspirar mudanças de atitudes e comportamentos. 


\section{REFERÊNCIAS}

[1] Aguiar, B., Correia, W., \& Campos, F. (2011). Uso da Escala Likert na Análise de Jogos. Anais do X Simpósio Brasileiro de Games e Entretenimento Digital, 07-09 de novembro de 2011 Salvador.

[2] Bristot, P. C., Pozzebon, E., \& FRIGO, L. B. (2017). A representatividade das mulheres nos games. XVI SBGames. Curitiba.

[3] Calvillo Gámez, E. H., Cairns, P., \& Cox, A. L. (2009, September). From the gaming experience to the wider user experience. In Proceedings of the 23rd british hci group annual conference on people and computers: Celebrating people and technology (pp. 520-523). British Computer Society.

[4] Calvillo-Gámez, E. H., Cairns, P., \& Cox, A. L. (2015). Assessing the core elements of the gaming experience. In Game user experience evaluation (pp. 3762). Springer, Cham.

[5] Cavalcante, R. B., Calixto, P., \& Pinheiro, M. M. K. (2014). Análise de conteúdo: considerações gerais, relações com a pergunta de pesquisa, possibilidades e limitações do método. Informação \& Sociedade: Estudos, 24(1), 13-18.

[6] Constanti, G. (2018, May 18) Descolada de gigantes do setor, produção de indie games cresce no País. Carta Capital, Retrieved from https://www.cartacapital.com.br/cultura/descolada-de-gigantes-do-setorproducao-de-indie-games-cresce-no-pais/

[7] Costa, J. L. (2019). Memória e des-memória discursivas no movimento ciberfeminista. Revista Eletrônica de Estudos Integrados em Discurso e Argumentação.

[8] Couto, M. T., \& Schraiber, L. B. (2013). Machismo Hoje no Brasil: uma análise de gênero das percepções dos homens e das mulheres. Mulheres Brasileiras e Gênero nos Espaços Público e Privado: uma década de mudanças na opinião pública. São Paulo: Fundação Perseu Abramo, 47-61.

[9] da Silva, D. S., \& de Souza, S. L. (2017). Diversidade sociocultural e relações de poder no Brasil. Revista Labirinto, 26(2), 281-296.

[10] da Silva, J. P., Furtado, K. B., Pinheiro, M. J. G., de Freitas, R. F., \& de Brito, T. M. (2016). VIOLÊNCIA DOMÉSTICA NO BRASIL. Revista do Curso de Direito da Uniabeu, 6(1), 67-78.

[11] Dunn, B. K., Galletta, D. F., Hypolite, D., Puri, A., \& Raghuwanshi, S. (2013, January). Development of smart phone usability benchmarking tasks. In 2013 46th Hawaii International Conference on System Sciences (pp. 1046-1052). IEEE.

[12] Giannotti, V. (2004). O Dia da Mulher nasceu das mulheres socialistas. Núcleo Piratininga de Comunicação, 8(03).

[13] Lacy, M. L. (2000). Poder das cores no equilíbrio dos ambientes. Editora Pensamento.

[14] Limeira, C. F. D., Rosa, J. G. S., \& Pinho, A. L. S. D. (2015). Avaliação, análise e desenvolvimento de jogo sério digital para desktop sobre sintomas e procedimentos de emergência do Acidente Vascular Cerebral. Blucher Design Proceedings, 2(2), 398-409.

[15] Lowdermilk, T. (2013). User-centered design: a developer's guide to building user-friendly applications. " O'Reilly Media, Inc.".

[16] McCarthy J, Wright P (2004) Technology as Experience. MIT Press, Cambridge, MA

[17] Michael, D. R., \& Chen, S. L. (2005). Serious games: Games that educate, train, and inform. Muska \& Lipman/Premier-Trade.

[18] Nacke L.E, Anders Drachen, and Stefan Göbel. Methods for evaluating gameplay experience in a serious gaming context. International Journal of Computer Science in Sport, 9(2):1-12, 2010

[19] Ratan, R. A., \& Ritterfeld, U. (2009). Classifying serious games. In Serious games (pp. 32-46). Routledge.

[20] Ribeiro, M. P. (2008). Feminismo, machismo e música popular brasileira. Revista Eletrônica do Instituto de Humanidades, 7(25).

[21] Santa Rosa, J. G., \& de Moraes, A. (2010). Avaliação e projeto no design de interfaces. $2 \mathrm{AB}$.

[22] Santos, C. J. (2017). Crimes de preconceito e de discriminação. Editora Saraiva.

[23] Silva, M. C., \& Mendes, O. M. (2015). As marcas do machismo no cotidiano escolar. Caderno Espaço Feminino, 28(1).

[24] Welzer-Lang, D. (2001). A construção do masculino: dominação das mulheres e homofobia. Revista Estudos Feministas, 9(2), 460-482.

[25] Wright, W., \& Bogost, I. (2007). Persuasive games: The expressive power of videogames 